\title{
SUIREN FORTRESS AS DESCRIBED BY A. S. UVAROV
}

\author{
Yuriy M. Mogarichev \\ Institute of Archaeology of Crimea, RAS; \\ Crimean Republican Institute of Postgraduate Pedagogical Education, Simferopol, Russian Federation
}

\begin{abstract}
Introduction. The article introduces into scientific parlance description of Suiren fortress prepared by A. S. Uvarov within the $4^{\text {th }}$ chapter From Dnieper to Taurida mountains of the $3^{\text {rd }}$ unpublished issue of Studies on antiquities of Southern Russia and Black Sea Coasts, that now is preserved in the State Historical Museum at the department of manuscripts and early printed books.

Methods. Suiren fortress is one of the most mysterious and unexplored cave towns. The time of the construction of fortification dates back between the $6^{\text {th }}$ and the $12^{\text {th }}$ centuries. By the time of Uvarov visit (1848), the hillfort had been unknown both among researchers and general public.

Analysis. The Suiren Story by Uvarov consists of two unequal parts: brief survey of architectural lasts of the defense constructions and detailed description of the church, located on the second floor of defense tower. The author pays special attention to fresco murals, which had remained by that time. It was de-facto the first detailed overview of the object in historiography (apart from brief survey of P.I. Keppen). Uvarov was accompanied by painter M. Vebel who made sketches of fortress defense lines and identifiable in 1848 fragments of fresco paintings. The description of Uvarov had remained unknown by researchers of the fortress in mid $19^{\text {th }}$ - beginning of the $21^{\text {st }}$ century. On the contrary, paintings of M. Vebel included in so-called 'unpublished album of A. S. Uvarov' became a primary source for future generation of researchers because a part of defense wall ruined in the second half of the $19^{\text {th }}$ century and murals had become mostly indistinguishable by mid $20^{\text {th }}$ century.

Results. The publication of the Uvarov description will enhance our understanding about the nature of fresco paintings of Suiren fortress.

Key words: Byzantium, Crimea, cave towns, Suiren fortress, frescos, A. S. Uvarov.

Citation. Mogarichev Yu.M. Suiren Fortress as Described by A. S. Uvarov. Vestnik Volgogradskogo gosudarstvennogo universiteta. Seriya 4, Istoriya. Regionovedenie. Mezhdunarodnye otnosheniya [Science Journal of Volgograd State University. History. Area Studies. International Relations], 2018, vol. 23, no. 5, pp. 105-118. (in Russian). DOI: https://doi.org/10.15688/jvolsu4.2018.5.9
\end{abstract}

УДК 75.052(477.75)+72.684(477.75)

ББК $63.3(0) 4$

Дата поступления статьи: 12.05.2018

Дата принятия статьи: 20.09.2018

\section{СЮЙРЕНЬСКАЯ КРЕПОСТЬ В ОПИСАНИИ А.С. УВАРОВА}

\author{
Юрий Миронович Могаричев \\ Институт археологии Крыма РАН; \\ Крымский республиканской институт постдипломного педагогического образования, \\ г. Симферополь, Российская Федерация
}

Аннотация. Настоящая публикация вводит в научный оборот описание Сюйреньской крепости, со-
ставленное А.С. Уваровым в рамках подготовки четвертой главы «От Днепра до Таврических гор» третьего,
неопубликованного выпуска «Исследований о древностях Южной России и берегов Черного моря» (ныне
хранится в архиве Отдела письменных источников Государственного исторического музея).
Сюйреньская крепость - один из наиболее загадочных и малоизученных «пещерных городов». Время
сооружения здесь укрепления различные исследователи датируют в диапазоне от VI до XII века. К моменту
посещения А.С. Уваровым Крыма (1848 г.) данное городище было практически неизвестно как исследовате-
лям, так и широкой общественности. 


\section{ВИЗАНТИЙСКАЯ ТАВРИКА}

«Сюйреньский сюжет» А.С. Уварова состоит из двух неравномерных частей: краткого обзора архитектурных остатков оборонительных сооружений и подробного описания церкви, расположенной на втором этаже оборонительной башни. Особое внимание исследователь уделил фресковым росписям, сохранившимся тогда в храме. Это фактически первый в историографии (за исключением краткого описания П.И. Кеппена) подробный обзор данного объекта. Сопровождавшим А.С. Уварова художником М. Вебелем были сделаны зарисовки оборонительной линии крепости и фрагментов различимых в 1848 г. фресковых росписей. Описание А.С. Уварова осталось неизвестным исследователям Сюйреньской крепости середины XIX начала XXI века. Рисунки же М. Вебеля, вошедшие в так называемый «Неизданный альбом А.С. Уварова», стали первоисточником для всех последующих поколений ученых: уже во второй половине XIX в. часть оборонительных стен обрушилась, а росписи, доступные природным стихиям, уже к середине XX в. были практически неразличимы.

Публикация уваровского описания позволит расширить наши представления о характере фресковой живописи Сюйреньской крепости.

Ключевые слова: Византия, Крым, «пещерные города», Сюйреньская крепость, фрески, А.С. Уваров.

Цитирование. Могаричев Ю. М. Сюйреньская крепость в описании А.С. Уварова // Вестник Волгоградского государственного университета. Серия 4, История. Регионоведение. Международные отношения. 2018. - T. 23, № 5. - C. 105-118. - DOI: https://doi.org/10.15688/jvolsu4.2018.5.9

Введение. В ряде предыдущих работ нами были опубликованы описания отдельных «пещерных городов» Горного Юго-Западного Крыма: Тепе-Кермена [19] и Эски-Кермена [18], - составленные А.С. Уваровым в рамках работы над третьим выпуском (гл. 4-7) «Исследований о древностях Южной России и берегов Черного моря». Была также введена в научный оборот уваровская версия происхождения скальной архитектуры Крыма [17]. Сюжет о «пещерных городах» должен был стать частью четвертой главы «От Днепра до Таврических гор». Однако данный труд не был автором закончен и издан. Рукопись ныне хранится в Отделе письменных источников Государственного исторического музея (ГИМ) [26]. Настоящая публикация представляет уваровский сюжет, посвященный Сюйреньской крепости. Описание выполнено на листах формата A3 черными чернилами и содержит авторские правки и зачеркивания в тексте. Следовательно, перед нами рабочий вариант рукописи. В тексте имеется несколько ремарок, написанных красными чернилами, предполагающих в дальнейшем вставку текста.

Методы. Данное городище площадью 1,7 га расположено на окруженной высокими обрывами оконечности мыса Куле-Бурун (Башенный мыс), недалеко от современного с. Малое Садовое Куйбышевского сельского поселения Бахчисарайского района Республики Крым (рис. 1, 2).

В 1930-1932 гг. территорию поселения обследовали Н.И. Репников и Е.В. Веймарн
[4, с. 116-123]. В 60-е гг. прошлого века здесь проводились небольшие археологические работы экспедициями под руководством Д.Л. Талиса [23] и И.А. Баранова [2]. В конце 1970-х гг. исследования велись Ю.С. Ворониным и В.Н. Даниленко [6; 8] (подробнее об истории изучения Сюйреньской крепости см.: [13]).

Сюйреньская крепость - один из наиболее загадочных и малоизученных «пещерных городов». Время сооружения здесь укрепления различные исследователи датировали в диапазоне от VI до XII в.:

- VI-VII вв. (послеюстиниановская пора) (Н.И. Репников [21, с. 205], С.Б. Сорочан [22, c. 204-206]);

- VI в. (А.Л. Якобсон [27], В.Л. Мыц [20, c. 135]);

$-\mathrm{V}-\mathrm{VII}$ вв. (Е.В. Веймарн [5, с. 76]);

- вторая половина VIII - Х в. (И.А. Баранов [3, с. 59-62], Ю.С. Воронин, В.В. Майко, В.А. Кутайсов [6, с. 458-459]);

- середина IX в. (А.И. Айбабин [1, c. 218]);

- рубеж IX-X вв. (В.Н. Даниленко [8, c. 39-42]);

- XI-XII вв. (Д.Л. Талис [24]).

Очевидно, что возведение здесь оборонительных стен, судя по их архитектурному решению, связано с деятельностью византийской администрации и произошло это до $\mathrm{X}$ века. А вот на каком этапе, имеющиеся на данный момент археологические материалы не позволяют однозначно ответить. То ли это слу- 
чилось в конце VI - начале VII в., тогда Сюйреньская крепость была основана одновременно с Мангупской, Эски-Керменской и другими, то ли возведение крепостных стен на мысе Куле-Бурун произошло в середине IX в. и связано было с созданием в Крыму фемы Климатов. В тот период византийская администрация производила реконструкцию оборонительных систем ряда уже существовавших крепостей. Возможно, для защиты подступов к центру Крымской Готии - Доросу (Мангуп), и для контроля пути на Южный берег Крыма (рядом с Сюйреньской крепостью проходит и ныне функционирующая дорога, ведущая из Внутренней гряды через Ай-Петри на Южный берег) и возводится новое укрепление. Значение Сюйреньской крепости возрастает в первой половине XV в.: она становится северным форпостом княжества Феодоро. Вероятно, укрепление функционировало до 1475 г., когда оно было захвачено и разгромлено турками. Вполне возможно, что в XVI в., а вероятно и раннее, это поселение называлось Сциварин и находилось на территории проживания крымских готов. Наиболее известным памятником Сюйреньской крепости является фортификационная система, состоящая из двух куртин, сходящихся под тупым углом, и круглой башни между ними. На нижнем этаже башни находились бойницы, а на втором в XIII-XV вв. функционировала церковь, стены и купол которой были полностью покрыты фресковой росписью. В настоящее время купол верхнего этажа разрушился, а фрески практически полностью уничтожены. В 300 м к юго-востоку от рассматриваемой оборонительной линии (впереди нее) мыс перегораживает еще одна стена длиной 155 м, толщиной 2,2 м и с сохранившейся высотой 1,5 м. Археологические материалы не дают оснований для ее датировки. Возможно, она была сооружена в период Феодоро и служила передовой защитной линией крепости. Вероятно, крепость была застроена каменными домами, по крайней мере в XII-XV вв. (археологически исследована лишь небольшая площадь поселения). Под северо-восточным обрывом Куле-Буруна выявлены тарапаны, а в долине остатки нескольких сельских поселений и могильников (см. подробнее: [14, с. 145-147; 15, c. 190-195]).
К моменту посещения А.С. Уваровым Крыма (1848 г.) Сюйреньская крепость практически неизвестна как исследователям, так и широкой общественности. П.И. Кеппен, автор «Крымского сборника», изданного в 1837 г. [12] и, наряду с трудом Ф. Дюбуа де Монпере $[10 ; 28]$, являвшегося основным источником для уваровских штудий, писал: «На вершине (скалы. - Ю. М.) видна башня, доныне не посещенная ни одним из путешественников, писавших о Крыме» [12, с. 291-292]. Ф. Дюбуа де Монпере, автор самого подробного описания «пещерных городов» первой половины XIX в. (1843 г.), до Сюйрени так и не добрался. «От ущелья, ведущего к Мангупу, я отправился прямо в Албат, который находится у входа в ущелье Сюрени, на реке Бельбек. <..> На вершине скалы слева мой проводник показал мне одинокую башню, которую он назвал Кудлет-Кале. Ее расположение, вместе с пейзажем, напоминало дикие скалы саксонской Швейцарии, которые нередко увенчаны руиной, возвышающейся над горными вершинами. Я не имел случая ее посетить» $[10$, c. 261].

Анализ.

Текст рукописи А.С. Уварова «Берега Бельбека. Сюйренская башня»"

Л. 63

(Красными чернилами: Описание местности по плану Табл. LIV - обозначить пещеры. - описать крепость в... (2 слова неразборчиво. - Ю. М.) все есть - обозначить гробницы.)

Сюйренская башня и греческие гробницы ${ }^{2} \mathrm{y}$ деревни Таш-Бастан-Сюйрень ${ }^{3}$ свидетельствуют о бывшем здесь греческом поселении. Кеппен предполагает, что во время Готов это место называлось Сциварин или Шурен. (Ссылка на полях: Сбор. Стр. $292^{4}$.)

Очень важно изучить Сюйренскую башню, как редкий пример церкви, находящейся во втором ярусе. На таблице LIII представлена башня и часть главной стены с южной стороны ${ }^{5}$. Кладка всех этих построек сдвинута на цементе, с примесью мелких кругловатых камушков (fapilli). Она вероятно сделана византийцами, из материалов,

Л. 63 об.

оставшихся в развалинах Готского города ${ }^{6}$. Толщина стен в два аршина. В стенах башни, видны еще места, где лежали перекладины, разделяющие башню на два яруса. Внешнею шириною ярусы в 4 аршина 10 вершков. Так как расстояние между 
балками было везде равное, то можно заключить, что не было внутреннего сообщения между обоими ярусами ${ }^{7}$. В верхнем ярусе была церковь, в которую вероятно входили посредством прохода через арку, представленную на левой стороне башни (Табл. LIII) и по которой шла дорога к двери, устроенной на С3 (стороне? - Ю. М.). Алтарь был обращен на юго-восток (по компасу). Церковь освещалась тремя окнами заалтарными. Над ними по круглому своду (Кеппен, стр. 293) начиналась живопись, писанная на известке (al fresco). Она много пострадала и почти везде видны (Красными чернилами: просвечиваются.) плитки свода ${ }^{8}$. Фрески составляли полосу изображений, идущих вокруг купола (см. Табл. LV, планы I и II) ${ }^{9}$, и образа между собою отделены были рамками. Сверх того, в нише одного из боковых окон

\section{Л. 64}

видны также остатки живописи, а на самой середине купола написан был осьмиконечный крест (красными чернилами. - Ю. М.) и при нем от части над письменами IC, XC, HN, KA. Да сверх того буквы Ф Н (обе дважды) X, и I ными чернилами: срисовать или описать все фрески. Кеппен, стр. 293.)

Эти фрески принадлежат к древнейшим остаткам греческого письма, сохранившегося в Крыму. На табл. LV, план № I и II представлены фрески, идущие полосами по верх окон. Сырость и холода повредили (одно слово неразборчиво. -Ю. М.) красками, доселе сохранилась только подмалевка, которую всегда делали с охрою, они придают этот общий, охревый цвет всем фрескам. В некоторых только местах, над охрою, сохранились только следы красной краски. Все прочия цвета совершенно уничтожились.

(Слева черныли чернилами: Кеппен, стр. 292, говорит, что эти фрески Корсунского письма. О Корсунском письме смотрите его статьи ${ }^{10}$. (Далее 4 строчки неразборчиво. - Ю. М.)

(Слева на полях карандашом: Свиток бумаги с поперечными полосками вместо букв. Женщины молящиеся, у купели видны две молящиеся женщины. Свыше драпировки удивительной (2 слова неразборчиво. - Ю. М.) отделки, они писаны белой краской ${ }^{11}$.)

(Слева на полях красными чернилами: Чтобы определить значение этих фресок, сравнив с модными образами, имеем в виду порядок описываемый в Manuil d' Iconographie ${ }^{12}$.)

В 1867 г. Сюйренькое укрепление посетил Г.Э. Караулов. В 1870 г. в Новороссийском календаре на 1871 г. он опубликовал подробное описание памятника [11]. В отношении росписей он отметил следующее: «Это явно священные изображения, писанные по извести живыми и ясными красками и принадлежат, по видимому, к лучшей эпохе византийской живописи. Вокруг плафона ясно можно разглядеть только одну фигуру с ореолом над головою. Как кажется, это фигура Божией Матери. Затем следующая фигура, кажется Спасителя, тоже с ореолом над головою, обозначается довольно отчетливо; но судить о значении всех прочих фигур и украшений трудно, так как обвалившаяся штукатурка унесла все верхние их части. <.. > Но стан, руки, ноги и платье сохранились хорошо, почти у всех этих фигур. Лица всех фигур, которые можно разглядеть, а равно и открытые части тела, то есть шея, руки и ноги - весьма правильного и хорошего рисунка; тоже самое должно сказать и обо всех драпировках. Краски хорошо сохранились только темно-коричневая, желтоватая и красноватая» [11, с. 6-7]. Он также видел изображение восьмиконечного креста и монограммы IC, XC, NH, KA, «но перед $\mathrm{N}$ тут стоит еще $\mathrm{P}$, или $\Phi$, а затем только Н, и, нам кажется, еще другие буквы или украшения, которых нельзя распознать» [11, с. 6-7]. Свою статью Г.Э. Караулов дополнил зарисовками укреплений (рис. 5) и остатков фресок (рис. 6).

Е.В. Веймарн и Н.И. Репников, посвятившие Сюйреньской крепости отдельную статью, отметили приоритет зарисовки М. Вебеля над рисунком Г.Э. Караулова [4, c. 121]. Они различали среди росписей: «изображения пророков, один из них - с развернутым свитком», «композицию рождества Христова на фоне горного пейзажа. В пещере - лежащая на ложе богоматерь у яслей. На переднем плане у купели - две фигуры служанок. С краю направо - согбенная фигура Иосифа. Далее, в специальном обрамлении - низ прямоличной фигуры в пышно орнаментированном одеянии. Еще дальше шла, по-видимому, композиция Благовещения. Фигуры архангела и богоматери в рост. <..> В юго-восточной нише окна замечаются контуры фигур двух ангелов в рост с рипидами, а в замке арки написан большой восьмиконечный крест с соответствующими буквами» $[4$, с. $121-$ 122]. Исследователи датировали росписи XII-XIII в. [4, с. 121-122]. 
О.И. Домбровский отметил прогрессирующую утрату фресковых росписей: «В настоящее время... от композиции Рождества осталась лишь часть возлежащей фигуры богоматери с совершенно утраченным ликом. Еле различимы теперь фигуры служанок у купели, исчезла вся верхняя часть согбенной фигуры Иосифа. Не менее пострадала и композиция Благовещения. Изображения в нише окна... полностью утрачены» $[9$, с. 56]. Исследователь осторожно датировал росписи XIII вв. [9, с. 57].

Результаты. Публикуемое в настоящей работе описание А.С. Уварова осталось неизвестным исследователям Сюйреньской крепости середины XIX - начала XXI века. При этом зарисовки М. Вебеля, вошедшие в так называемый неизданный альбом А.С. Уварова, стали первоисточником для всех последующих поколений ученых: уже во второй половине XIX в. часть оборонительных стен обрушилась, а росписи, доступные природным стихиям, уже к середине XX в. были практически неразличимы (рис. 7). Публикация уваровского описания позволит расширить наши представления о первоначальном виде оборонительных сооружений Сюйреньской крепости и характере фресковой живописи церкви, функционировавшей на втором этаже оборонительной башни.

\section{ПРИМЕЧАНИЯ}

${ }^{1}$ Орфография и пунктуация источника сохранены.

2 Вероятно, имеются в виду упоминаемые П.И. Кеппеном греческие надгробия в деревне Таш Баскан Сюйрень [12, с. 292].

${ }^{3}$ П.И. Кеппен пишет, что деревня Таш Баскан Кой, или Таш Баскан Сюйрень, расположенная у подножия Сюреньской крепости, находится между деревнями Кучук-Сюйрень (соврем. с. Малое Садовое Куйбышевского сельского поселения Бахчисарайского района) и Биюк-Сюйрень (соврем. с. Танковое Куйбышевского сельского поселения Бахчисарайского района) [12, с. 291]. В настоящее время территория Таш Баскан Кой входит в состав с. Малое Садовое. Е.В. Веймарн и Н.И. Репников Таш Баскан Кой называют несколько по-иному Таш-Басты [4, с. 115].

${ }^{4}$ Около 1560 г. австрийский посол в Константинополе Ожье Гислен де Бусбек встретил на рын- ке двух готов из Крыма и так их описал в своем «Четвертом турецком письме»: «Один из них был выше ростом, всем своим видом являвший некую врожденную простоту, так что казался фламандцем или батавом...; другой был пониже, более плотного телосложения, смуглый, по происхождению и речи - грек, но такой, который ввиду частой торговли приобрел немалое знание их языка. Первый же из-за соседства и частого общения с греками так впитал их речь, что забыл свою родную. Будучи вопрошен о природе и нравах того народа, отвечал он сообразно. По его словам, это воинственный народ, который и сегодня обитает во многих деревнях, из которых царек татар, когда он готовится к войне, набирает восемьсот пехотинцев с огнестрельным оружием, составляющих оплот его войск; главные их города называются: один - Манкуп, другой - Сциварин» (цит. по: [7, c. 95]). П.И. Кеппен, основываясь на созвучии названий, предположил, что татарское название Сюйрень происходит от готского Сциварин «прежнего названия того же места» [12, с. 292]. Данная точка зрения принята и в современной историографии. Несомненно, что Манкуп - городище Мангуп, средневековый Дорос, центр Крымской Готии. Соответственно, Сциварин, будучи созвучным с Сюйренью, логично локализуется на недалеко расположенной Сюйреньской крепости.

${ }^{5}$ Известно, что по поручению А.С. Уварова сопровождавшим его художником М. Вебелем был сделан ряд рисунков памятников Крыма [25, с. 167]. Из «Сюйреньского цикла» известны изображение оборонительных сооружений (рис. 3) и остатков фресковых росписей в церкви, некогда функционировавшей на втором этаже оборонительной башни (рис. 4).

${ }^{6}$ В данном случае А.С. Уваров ошибается, считая, что сначала укрепление здесь было построено готами, а затем сюда пришли византийцы. В современной историографии сложилось устойчивое представление, что начиная с эпохи Юстиниана I и до начала XIII в. Горный Юго-Западный Крым большую часть времени контролировался Византийской империей. Местное готское население (страна Дори Прокопия Кесарийского) при Юстиниане стало федератами империи, а организация к 841 г. фемы Климатов свидетельствует о полноценном вхождении данной территории в состав империи ромеев. Весь комплекс имеющихся на данный момент источников свидетельствует, что крепостное строительство здесь велось под контролем имперских чиновников (подробнее см. : [16, с. 5-72]).

7 Общая длина стен оборонительной линии составляет 94 м (по Д.Л. Талису) или 110 (по И.А. Баранову), высота $-4,8$ м, толщина $-2,5$ м. Они (два панциря с забутовкой между ними) сложены из 


\section{ВИЗАНТИЙСКАЯ ТАВРИКА}

массивных обработанных известняковых блоков, положенных на известковый раствор. Двухэтажная башня диаметром 8 м имела высоту 10 м. Она также была сложена из блоков вперевязь со стеной. $\mathrm{C}$ ее восточной стороны располагались сводчатые ворота шириной 3,2 м, а с западной - калитка. Межэтажные перекрытия были деревянными [14, c. 145-147].

${ }^{8}$ О плохой сохранности фресковых росписей за одиннадцать лет до А.С. Уварова писал П.И. Кеппен: «Ликов Святых нельзя уже видеть большею частию потому, что штукатурка обвалилась» $[11$, с. 293]. Он различал среди изображений сюжет Успения Богородицы (как вариант положе- ние в Гроб Спасителя), посередине восьмиконечный крест и остатки букв IC, XC, HN, KA, Ф Н (обе дважды), Х и I $\omega[11$, с. 293].

${ }^{9}$ См. рис. 4.

${ }^{10}$ Под «корсунским письмом» П.И. Кеппен понимал византийскую фресковую живопись, сохранившуюся в том числе и в ряде церквей Крыма (см.: [12, с. 40, сноска 54]).

11 В основном описание А.С. Уварова повторяет кеппеновское. Новым является только «Свиток бумаги с поперечными полосками вместо букв. Женщины молящиеся, у купели видны две молящиеся женщины».

12 Имеется в виду работа: [29]. 


\section{ПРИЛОЖЕНИЕ}

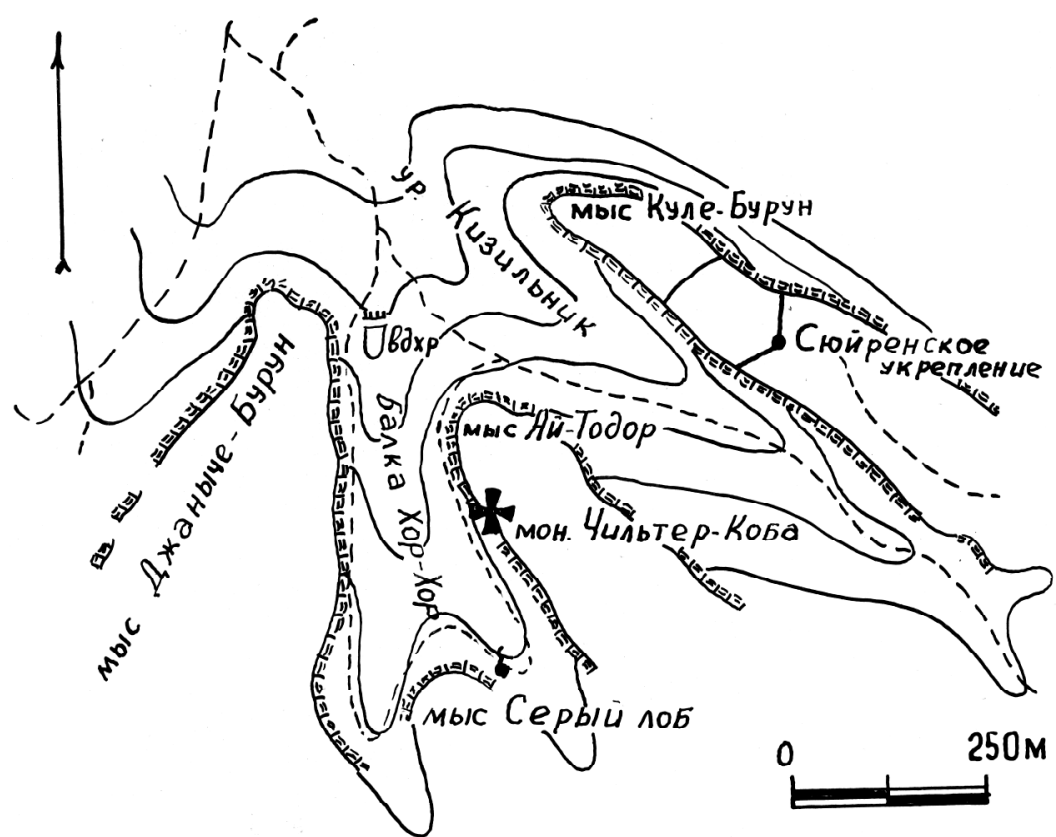

Рис. 1. План-схема расположения Сюйреньской крепости

Fig. 1. Scheme of the location of Suiren fortress

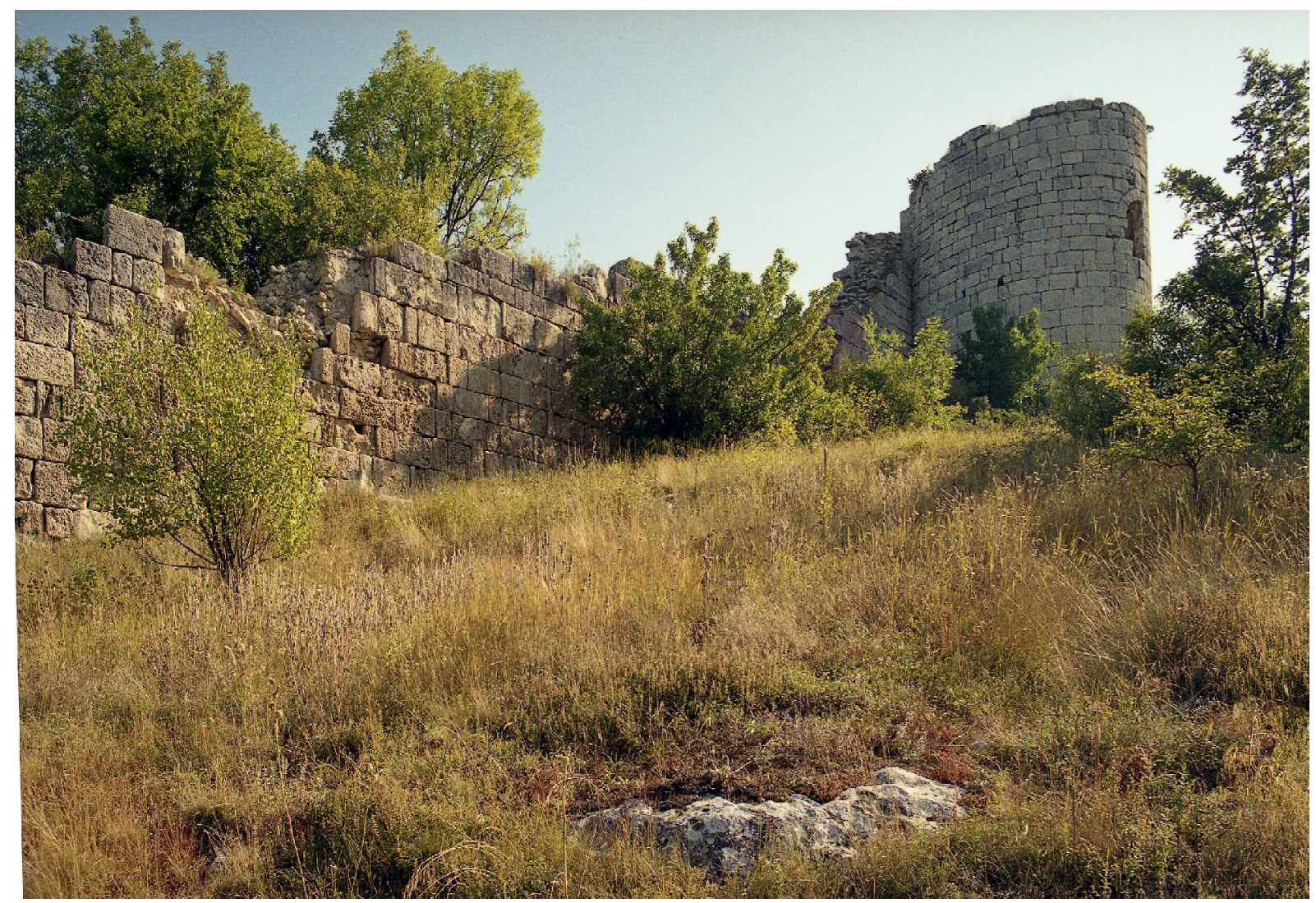

Рис. 2. Сюйреньская крепость. Современный вид

Fig. 2. Suiren fortress. Modern panorama 


\section{ВИЗАНТИЙСКАЯ ТАВРИКА}

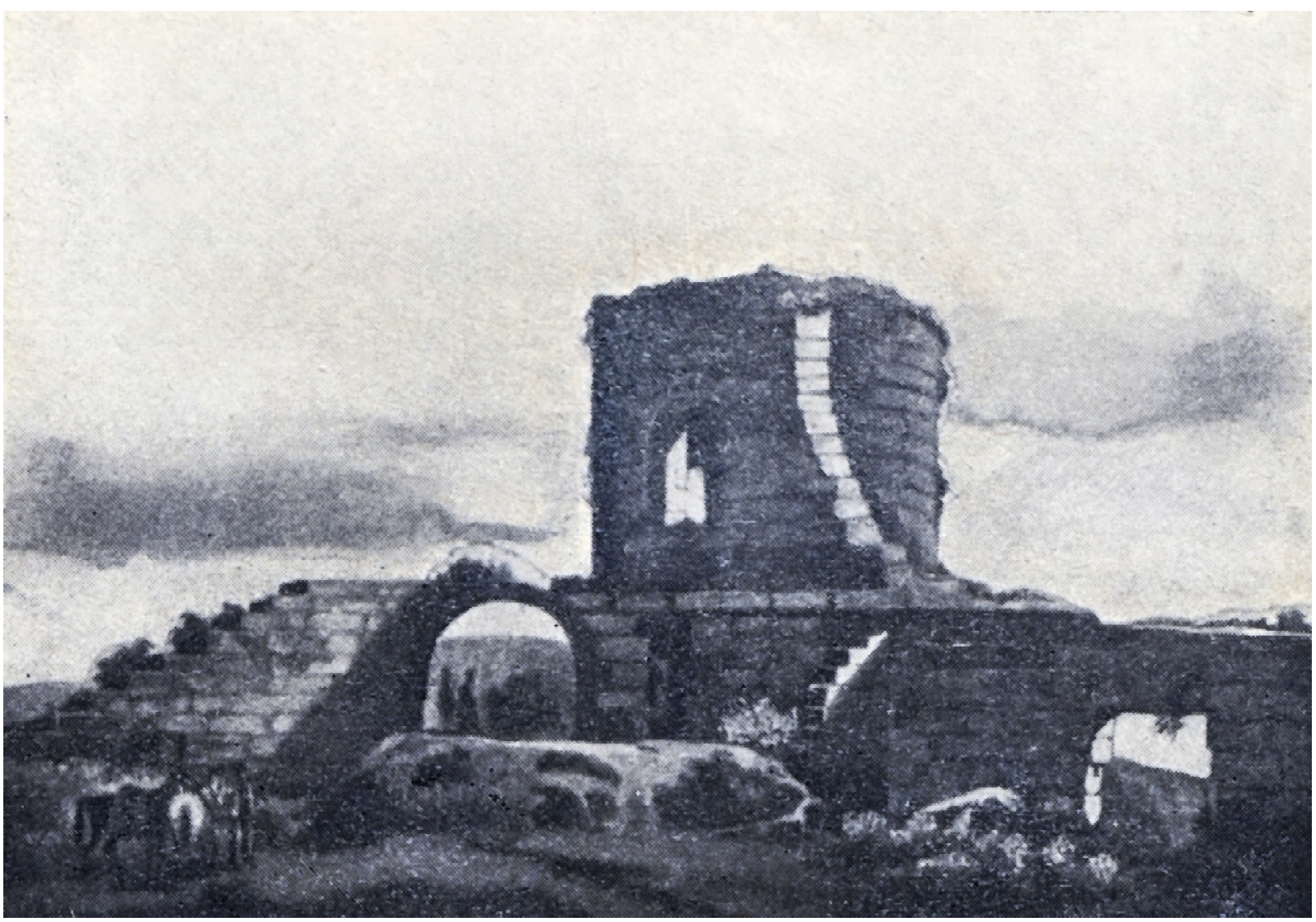

Рис. 3. Сюйреньская крепость. Из неизданного альбома А.С. Уварова

Fig. 3. Suiren fortress. From unpublished album of A. S. Uvarov 


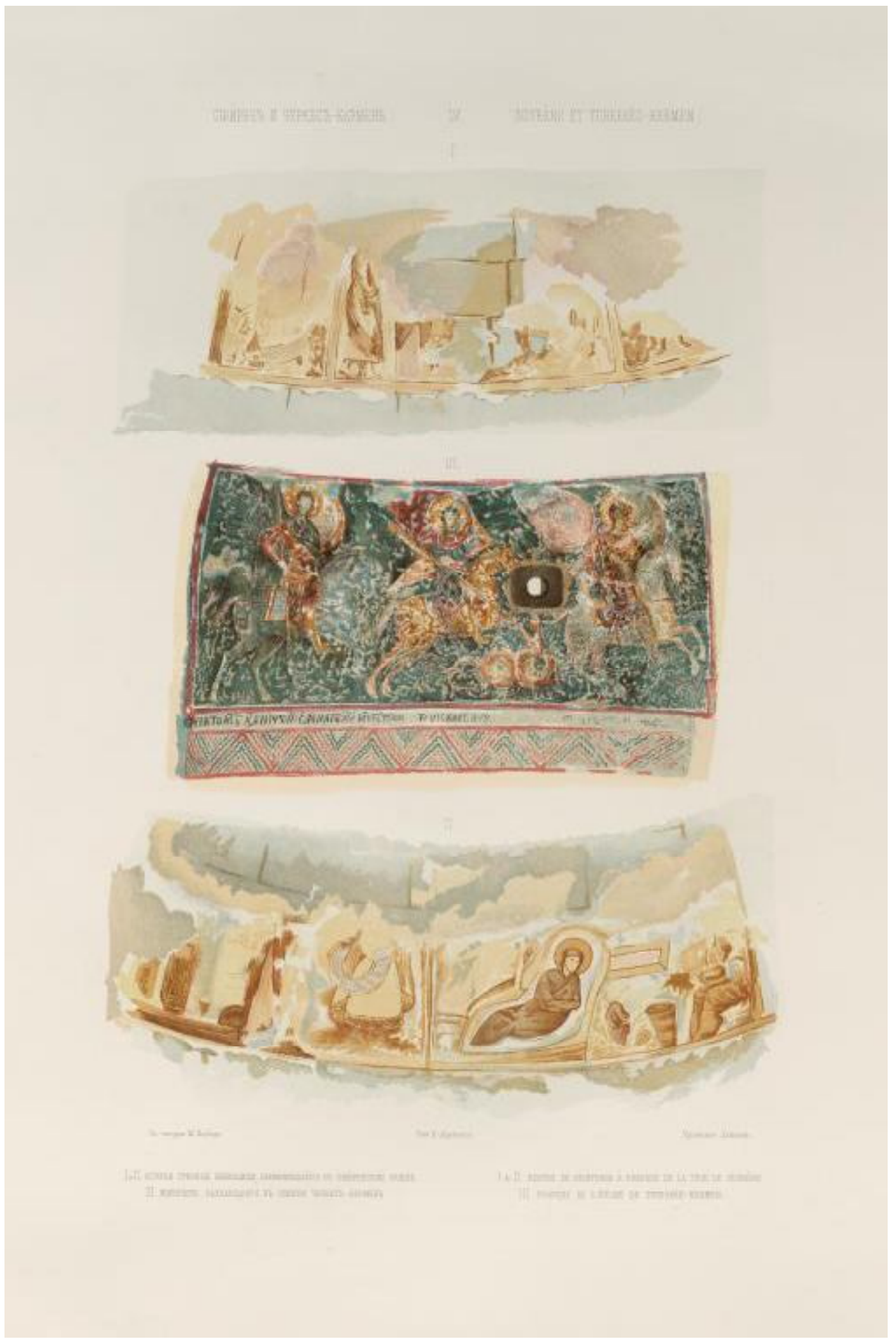

Рис. 4. Изображение фресковых росписей из средневековых церквей Крыма: росписи из церкви в Сюйреньской башне (вверху и внизу) и фреска из церкви «Трех всадников» (Эски-Кермен) (посередине). Из неизданного альбома А.С. Уварова

Fig. 4. Image of fresco paintings from medieval churches of Crimea: paintings from the church in Suiren fortress (at the top and at the bottom) and the fresco from the Three Riders church (Eski-Kerman) (in the middle). From unpublished album of A.S. Uvarov 


\section{ВИЗАНТИЙСКАЯ ТАВРИКА}

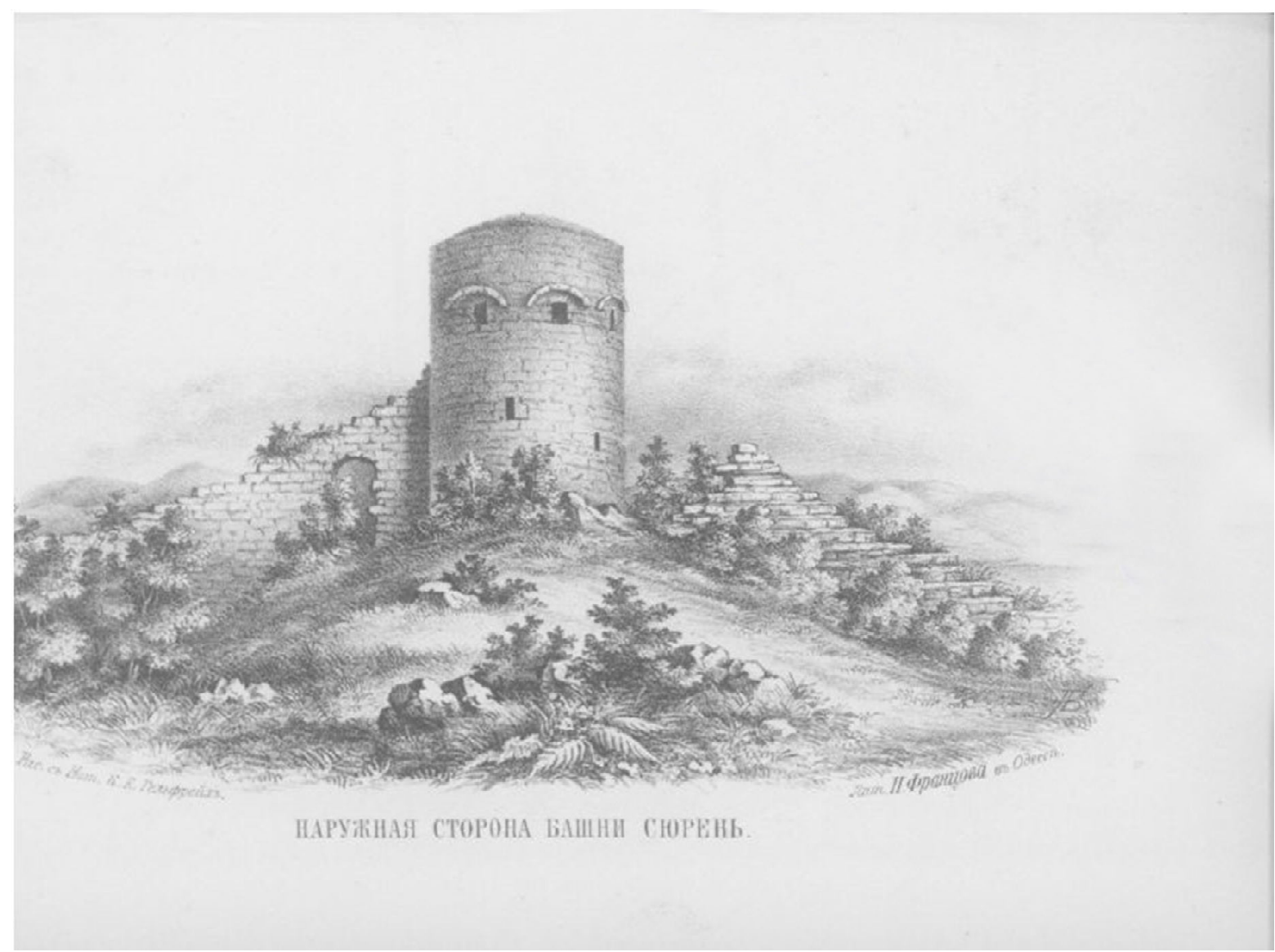

Рис. 5. Сюйреньская крепость по Г.Э. Караулову

Fig. 5. Suiren fortress according to G. E. Karaulov

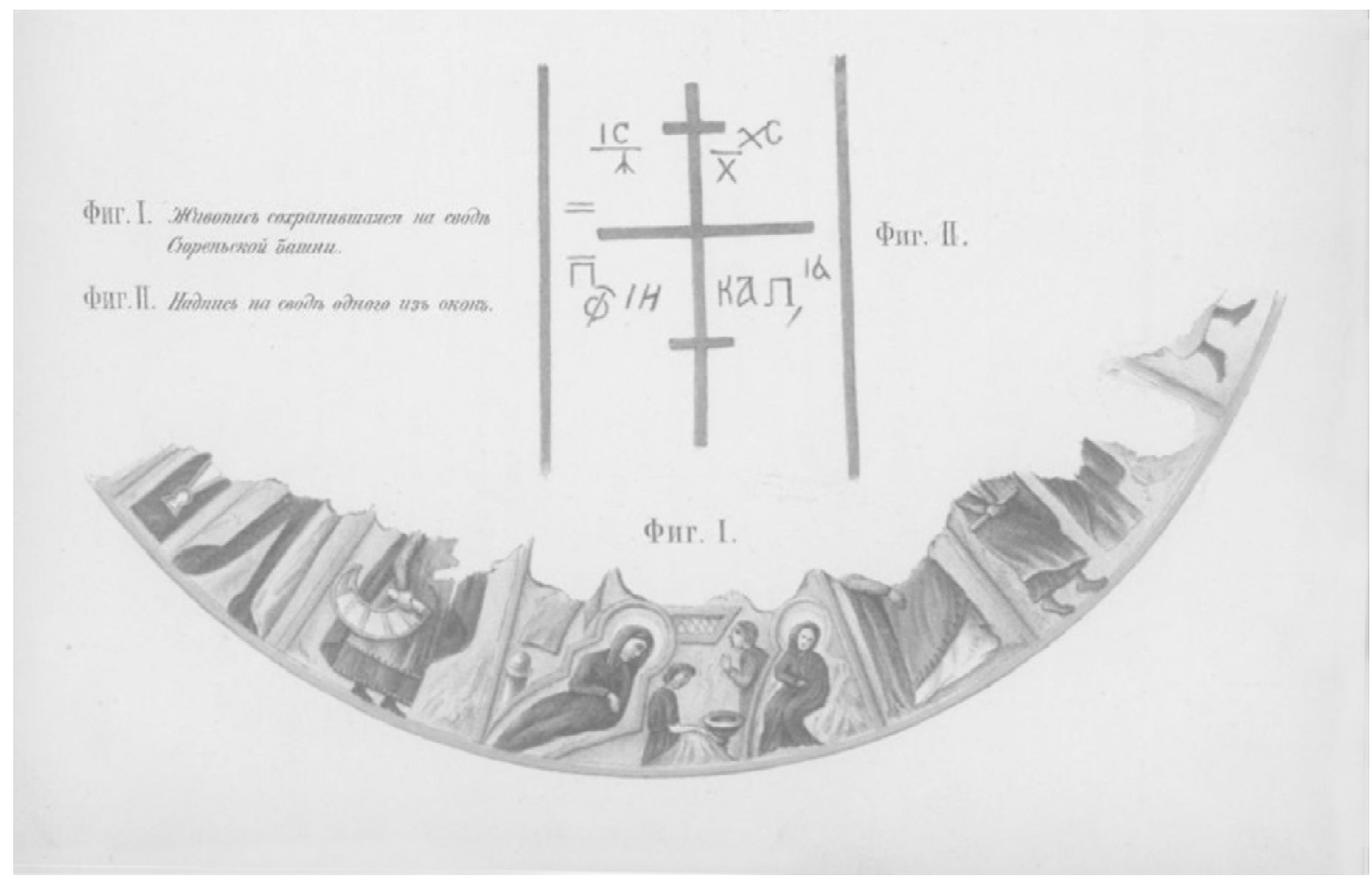

Рис. 6. Росписи в Сюйреньской башне по Г.Э. Караулову

Fig. 6. Paintings in Suiren fortress according to G. E. Karaulov 


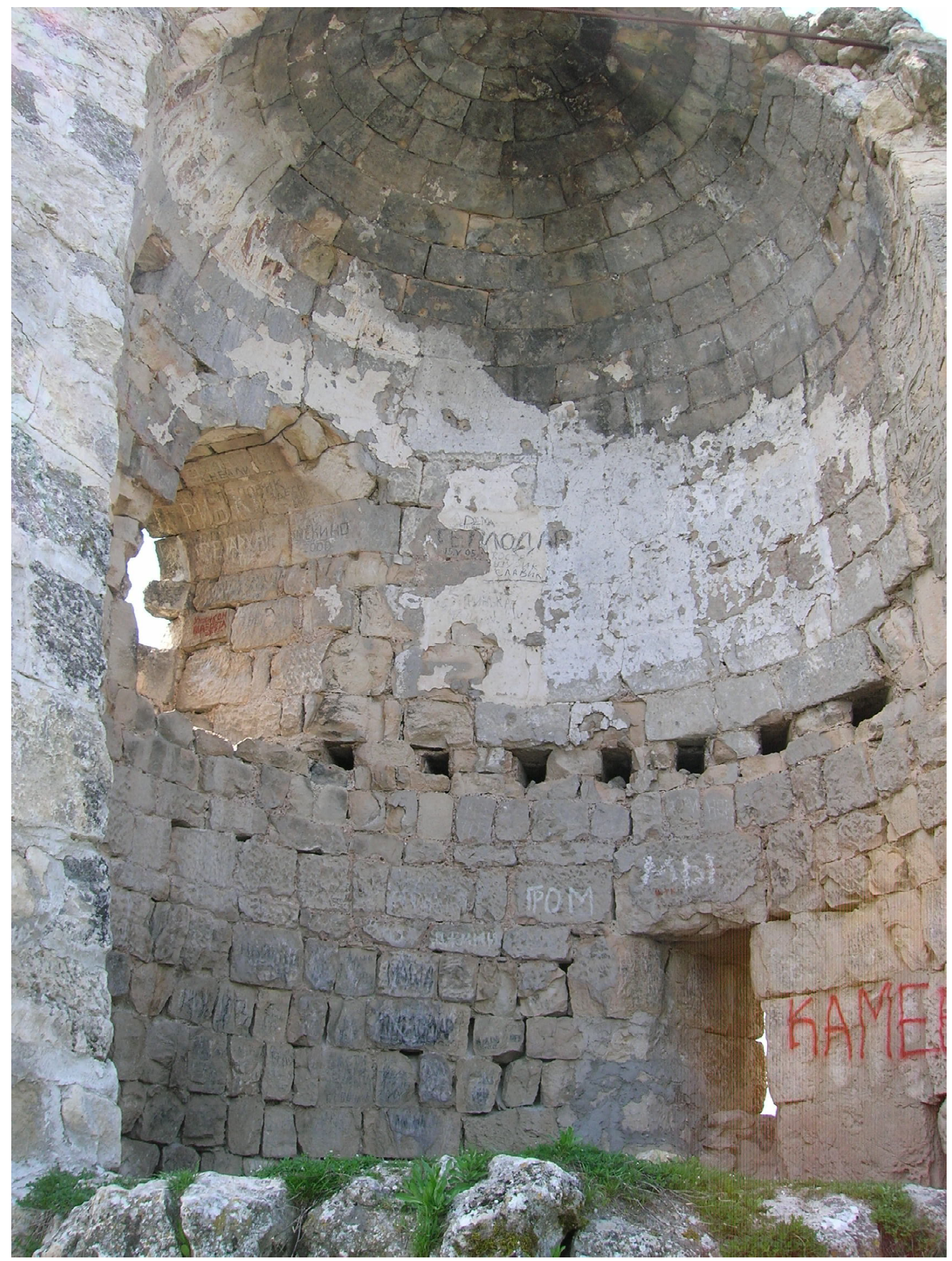

Рис. 7. Современное состояние фресок в Сюйреньской башне

Fig. 7. Current state of frescos in the Suiren fortress 


\section{СПИСОК ЛИТЕРАТУРЫ}

1. Айбабин, А. И. Этническая история ранневизантийского Крыма / А. И. Айбабин. - Симферополь : Дар, 1999. - 352 с.

2. Баранов, И. А. Археологические разведки на территории Сюйреньского укрепления в Крыму / И. А. Баранов // Археологические исследования на Украине 1968 г. - Киев : Наукова думка, 1971.Вып. 3. - С. 88-92.

3. Баранов, И. А. Таврика в эпоху раннего средневековья / И. А. Баранов. - Киев : Наукова думка, 1990.- 168 с.

4. Веймарн, Е. В. Сюйренское укрепление / Е. В. Веймарн, Н. И. Репников // Материалы ЭскиКерменской экспедиции 1931-1933 гг. - М. ; Л. : Гос. соц.-экон. изд-во, 1935. - С. 115-125. - (Известия государственной академии истории материальной культуры ; вып. 117).

5. Веймарн, Е. В. «Пещерные города» Крыма в свете археологических исследований 1954-1955 гг. / Е. В. Вейсмарн // Советская археология. - 1958. № 1. - С. 71-79.

6. Воронин, Ю. С. Археологические раскопки Сюйреньского укрепления 1978-79 гг. Раскоп 1 / Ю. С. Воронин, В. В. Майко, В. А. Кутайсов // История и археология Крыма.- 2014. - Вып. 1. С. $458-479$.

7. Ганина, Н. А. Крымско-готский язык / Н. А. Ганина. - СПб. : Алетейя, 2011. - 286 с.

8. Даниленко, В. Н. Археологические исследования Сюйреньского укрепления в Горном Крыму (раскоп II) / В. Н. Даниленко // Ученые записки Крымского федерального университета им. В.И. Вернадского. Исторические науки. 2016. - Т. 2 (68), № 1. - С. 39-48.

9. Домбровский, О. И. Фрески средневекового Крыма / О. И. Домбровский. - Киев : Наукова думка, 1966. - 110 с.

10. Дюбуа де Монпере, Ф. Путешествие в Крым / Ф. Дюбуа де Монпере ; пер. Т. М. Фадеевой. - Симферополь : Бизнес-Информ, 2009. $328 \mathrm{c}$.

11. Караулов, Г. Э. Древнее Сюйреньское укрепление и башня на Бельбеке / Г. Э. Караулов // Новороссийский календарь за 1871 г. - Одесса : Тип. П. Францова, 1870. - С. 3-24.

12. Кеппен, П. И. О древностях Южного берега Крыма и гор Таврических. Крымский сборник / П. И. Кеппен. - СПб. : Тип. АН, 1837. - 411 с.

13. Лавров, В. В. История изучения Сюйреньского укрепления / В. В. Лавров // История и археология Крыма.-2016. - Вып. III. - С. 344-347.

14. Могаричев, Ю. М. «Пещерные города» в Крыму / Ю. М. Могаричев. - Симферополь : Сонат, 2005. - 192 с.
15. Могаричев, Ю. М. Крым. «Пещерные города» / Ю. М. Могаричев. - Киев : Вища школа, 2010. $-280 \mathrm{c}$.

16. Могаричев, Ю. М. Средневековый Крым (VI - середина XIII в.) : История, религия, культура / Ю. М. Могаричев. - Симферополь : Бизнес-Информ, 2014. - 240 c.

17. Могаричев, Ю. М. К истории изучения пещерных сооружений горного Юго-Западного Крыма: А.С. Уваров о происхождении скальной архитектуры Таврики / Ю. М. Могаричев // Ученые записки Крымского федерального университета им. В.И. Вернадского. Исторические науки. -2017. T. 3 (69), № 2. - C. 94-110.

18. Могаричев, Ю. М. «Пещерный город» ЭскиКермен в описании А.С. Уварова / Ю. М. Могаричев // Вестник Волгоградского государственного университета. Серия 4, История. Регионоведение. Международные отношения. - 2017. - Т. 22, № 5. C. 56-74. - DOI: https://doi.org/10.15688/jvolsu4. 2017.5.6.

19. Могаричев, Ю. М. Городище Тепе-Кермен в описании А.С. Уварова / Ю. М. Могаричев // $\Lambda$ ЕПТОN : сб. ст. в честь археолога А.В. Пьянкова / ред.-сост. С. Н. Малахов. - Армавир ; Краснодар : В. Е. Шурыгин, 2018. - С. 110-117.

20. Мыц, В. Л. Укрепления Таврики X-XV вв. / В. Л. Мыц. - Киев : Наукова думка, 1991. - 164 с.

21. Репников, Н. И. Остатки укреплений ЭскиКермена / Н. И. Репников // Готский сборник. - Л. : Гос. соц.-экон. изд-во, 1932. - Т. ХІІ. - С. 187-212.(Известия Государственной академии истории материальной культуры ; вып. 1-8).

22. Сорочан, С. Б. Византийский Херсон. Очерки истории и культуры. В 2 ч. Ч. 1 / С. Б. Сорочан. Харьков : Майдан, 2005. -678 с.

23. Талис, Д. Л. Сюреньская крепость / Д. Л. Талис // Византийский временник. - 1972. - № 33. C. $218-229$.

24. Талис, Д. Л. Оборонительные сооружения Юго-Западной Таврики как исторический источник / Д. Л. Талис // Археологические исследования на юге Восточной Европы. - М. : Гос. ист. музей, 1974. - C. 109-110.

25. Тункина, И. В. А.С. Уваров и древности Южной России (конец 1840-х - начало 1850-х гг.) / И. В. Тункина // Погибшие святыни. Охраняется государством : Четвертая Рос. науч.-практ. конф. СПб. : [б. и.], 1996. - С. 163-181.

26. Уваров, А. С. Исследования о древностях Южной России и берегов Черного моря. Жители Таврических гор / А. С. Уваров // Архив Отдела письменных источников Государственного исторического музея. - Ф. 17. - Оп. 1. -Ед. хр. 196. - Л. 18 об. - 84.

27. Якобсон, А. Л. По поводу статьи Д.Л. Талиса «Сюйреньская крепость» / А. Л. Якобсон 
// Византийский временник. - 1974. - № 36. C. 193-194.

28. Dubois de Montpéreux, F. Voyage autour du Caucase, ches les Tcherkesses et les Abkhases, en Colchide, en Géorgie, en Arménie et en Crimée. In 6 vols. Vol. 6 / F. Dubois de Montpéreux. - P. : Libr. de Gide, 1843. -461 p.

29. Manuel d'iconographie chrétienne, grecque et latine / une introd. et des notes par M. Didron. - P. : Impr. Royale, 1845. -483 p.

\section{REFERENCES}

1. Aybabin A.I. Etnicheskaya istoriya rannevizantiyskogo Kryma [Ethnic History of Early Byzantine Crimea]. Simferopol, Dar Publ., 1999. 352 p. (in Russian).

2. Baranov I.A. Arkheologicheskie razvedki na territorii Syuyrenskogo ukrepleniya v Krymu [Archeological Survey in the Territory of Suiren Fortress in Crimea]. Arkheologicheskie issledovaniya na Ukraine $1968 \mathrm{~g}$. [Archeological Investigations in Ukraine, 1968]. Kiev, Naukova dumka Publ., 1971, vol. 3, pp. 88-92. (in Russian).

3. Baranov I.A. Tavrika v epokhu rannego srednevekovya [Taurica in the Early Middle Ages]. Kiev, Naukova dumka Publ., 1990. 168 p. (in Russian).

4. Veymarn E.V., Repnikov N.I. Syuyrenskoe ukreplenie [Suiren Fortress]. Materialy EskiKermenskoy ekspeditsii. Moscow; Leningrad, Gos. sots.-ekon. izd-vo Publ., 1935, pp. 115-125. (Izvestiya gosudarstvennoy akademii istorii materialnoy kultury [Bulletin of State Academy for the History of Material Culture]; vol. 117). (in Russian).

5. Veymarn E.V. «Peshchernye goroda» Kryma V svete arkheologicheskikh issledovaniy 19541955 gg. [Crimean "Cave Towns" in View of Archeological Investigations of 1954-1955]. Sovetskaya arkheologiya [Soviet Archaeology], 1958, no. 1, pp. 71-79. (in Russian).

6. Voronin Yu.S., Mayko V.V., Kutaysov V.V. Arkheologicheskie raskopki Syuyrenskogo ukrepleniya 1978-79 gg. Raskop 1 [Archeological Excavations of Suiren Fortress in 1978-1979. Excavation I]. Istoriya i arkheologiya Kryma [History and Archaeology of Crimea], 2014, vol. 1, pp. 458-479. (in Russian).

7. Ganina N.A. Krymsko-gotskiy yazyk [Crimean-Gothic Language]. Saint Petersburg, Aletheia Publ., 2011.286 p. (in Russian).

8. Danilenko V.N. Arkheologicheskie issledovaniya Syuyrenskogo ukrepleniya v Gornom Krymu (raskop II) [Archaeological Research of Suiren Fortification in the Mountainous Crimea (Excavation II)]. Uchenye zapiski Krymskogo federalnogo universiteta im. V.I. Vernadskogo. Istoricheskie nauki [Scientific Notes of V.I. Vernadsky Crimean Federal University. Historical Sciences], 2016, vol. 2 (68), no. 1, pp. 39-48. (in Russian).

9. Dombrovskiy O.I. Freski srednevekovogo Kryma [The Frescoes of Medieval Crimea]. Kiev, Naukova dumka Publ., 1966. 110 p. (in Russian).

10. Duboi de Monpere F. Puteshestvie v Krym [A Journey to Crimea]. Simferopol, Biznes-Inform Publ., 2009. 328 p. (in Russian).

11. Karaulov G.E. Drevnee Syuyrenskoe ukreplenie i bashnya na Belbeke [The Ancient Suiren Fortress and the Tower on the Belbek River]. Novorossiyskiy kalendar za $1871 \mathrm{~g}$. [Novorossiysk Calendar for 1871]. Odessa, Tip. P. Frantsova Publ., 1870, pp. 3-24. (in Russian).

12. Keppen P.I. O drevnostyakh Yuzhnogo berega Kryma i gor Tavricheskikh. Krymskiy sbornik [On Antiquities of Southern Coast of Crimea and Taurica Mountains. Crimean Collection]. Saint Petersburg, Tip. AN Publ., 1837. 411 p. (in Russian).

13. Lavrov V.V. Istoriya izucheniya Syuyrenskogo ukrepleniya [History of Research of the Suiren Fortification]. Istoriya i arkheologiya Kryma [History and Archaeology of the Crimea], 2016, vol. III, pp. 344347. (in Russian).

14. Mogarichev Yu.M. «Peshchernye goroda»v Krymu ["The Cave Towns" in Crimea]. Simferopol, Sonat Publ., 2005. 192 p. (in Russian).

15. Mogarichev Yu.M. Krym. "Peshchernye goroda» [Crimea. "The Cave Towns"]. Kiev, Vishcha shkola Publ., 2010. 280 p. (in Russian).

16. Mogarichev Yu.M. Srednevekovyy Krym (VIseredina XIII v.): istoriya, religiya, kultura [Medieval Crimea ( $6^{\text {th }}-$ mid $13^{\text {th }}$ Century): History, Religion and Culture]. Simferopol, Biznes-Inform Publ., 2014. 240 p. (in Russian).

17. Mogarichev Yu.M. K istorii izucheniya peshchernykh sooruzheniy gornogo Yugo-Zapadnogo Kryma: A. S. Uvarov o proiskhozhdenii skalnoy arkhitektury Tavriki [On the History of Researching Mountain South-West Crimea: A. S. Uvarov on the Origin of Taurida's Cliff Architecture]. Uchenye zapiski Krymskogo federalnogo universiteta imeni V. I. Vernadskogo. Istoricheskie nauki [Scientific Notes of V.I. Vernadsky Crimean Federal University. Historical Sciences], 2017, vol. 3 (69), no. 2, pp. 94-110. (in Russian).

18. Mogarichev Yu.M. The "Cave Town" of EskiKermen in A.S. Uvarov's Description. Vestnik Volgogradskogo gosudarstvennogo universiteta. Seriya 4. Istoriya. Regionovedenie. Mezhdunarodnye otnosheniya [Science Journal of Volgograd State University. History. Area Studies. International Relations], 2017, vol. 22, no. 5, pp. 56-74. DOI: https: //doi.org/10.15688/jvolsu4.2017.5.6. (in Russian). 


\section{ВИЗАНТИЙСКАЯ ТАВРИКА}

19. Mogarichev Yu.M. Gorodishche Tepe-Kermen v opisanii A.S. Uvarova [The Hillfort of Tepe-Kermen in A.S. Uvarovs' Description]. 1EПTON: Sbornik statey $v$ chest arkheologa Alekseya Vasilevicha Pyankova [LEPTON: Collection of Articles in Honor of Alexey V. Pyankov]. Armavir; Krasnodar, V.E. Shurygin Publ., 2018, pp. 110-117. (in Russian).

20. Myts V.L. Ukrepleniya Tavriki $X-X V v v$. [Fortifications of Taurica of the $10^{\text {th }}-15^{\text {th }}$ cent.]. Kiev, Naukova dumka Publ., 1991. 164 p. (in Russian).

21. Repnikov N.I. Ostatki ukrepleniy EskiKermena [Remainings of Eski-Kermen Fortifications]. Leningrad. Izvestiya gosudarstvennoy akademii istorii materialnoy kultury [Bulletin of State Academy for the History of Material Culture]. Gos. sots.-ekon. izd-vo Publ., 1932, vol. 12, pp. 187-212. (in Russian).

22. Sorochan S.B. Vizantiyskiy Kherson. Ocherki istorii i kultury. V 2ch. Ch. 1 [The Byzantine Kherson. Surveys of History and Culture. In 2 parts. Part 1]. Kharkov, Maydan Publ., 2005. 678 p. (in Russian).

23. Talis D.L. Syurenskaya krepost [Suiren Fortress]. Vizantiyskiy vremennik [BYZANTINA XPONIKA], 1972, no. 33, pp. 218-229. (in Russian).

24. Talis D.L. Oboronitelnye sooruzheniya YugoZapadnoy Tavriki kak istoricheskiy istochnik [The Defense Structures of Southwest Taurica as a Historical Source]. Arkheologicheskie issledovaniya na yuge Vostochnoy Evropy [Archaeological Studies in South-East Europe]. Moscow, Gosudarstvennyy istoricheskiy muzey Publ., 1974, pp. 109-110. (in Russian).

25. Tunkina I.V. A.S. Uvarov i drevnosti Yuzhnoy Rossii (konets 1840-kh - nachalo 1850-kh gg.) [A.S. Uvarov and Antiquites of the Southern Russia: end of the 1840s - beginning of the 1850s]. Pogibshie svyatyni. Okhranyaetsya gosudarstvom. Chetvertaya Rossiyskaya nauchno-prakticheskaya konferentsiya [The Lost Sacred Objects: Protected by the State. The $4^{\text {th }}$ Russian Scientific Conference]. Saint Petersburg, 1996, pp. 163-181. (in Russian).

26. Uvarov A.S. Issledovaniya o drevnostyakh Yuzhnoy Rossii i beregov Chernogo morya. Zhiteli Tavricheskikh gor [Studies on the Southern Russia and Black Sea Coast Antiquities. Inhabitants of Crimean Mountains]. Arkhiv Otdela pismennykh istochnikov Gosudarstvennogo istoricheskogo muzeya [Archive of the Department of Written Sources of State Historical Museum], F. 17, op. 1, ed. khr. 196,1. 18 ob.-84. (in Russian).

27. Yakobson A.L. Po povodu statyi D.L. Talisa «Syuyrenskaya krepost» [On the Article of D. L. Talis Suiren Fortress]. Vizantiyskiy vremennik [BYZANTINA XPONIKA], 1974, no. 36, pp. 193-194. (in Russian).

28. Dubois de Montpéreux F. Voyage autour $d u$ Caucase, ches les Tcherkesses et les Abkhases, en Colchide, en Géorgie, en Arménie et en Crimée. In 6 vols. Vol. 6. Paris, Libr. de Gide, 1843. 461 p.

29. Didron M., ed. Manuel d'iconographie chrétienne, grecque et latine. Paris, Impr. Royale, $1845.483 \mathrm{p}$.

\section{Information about the Author}

Yuriy M. Mogarichev, Doctor of Sciences (History), Professor, Leading Researcher, Institute of Archaeology of Crimea, RAS; Head of Department of Social and Humanities Education, Crimean Republican Institute of Postgraduate Pedagogical Education, Lenina St., 15, 295051 Simferopol, Russian Federation,mogara@rambler.ru, https://orcid.org/0000-0001-6057-2316

\section{Информация об авторе}

Юрий Миронович Могаричев, доктор исторических наук, профессор, ведущий научный сотрудник, Институт археологии Крыма РАН; заведующий кафедрой социального и гуманитарного образования, Крымский республиканской институт постдипломного педагогического образования, ул. Ленина, 15, 295051 г. Симферополь, Российская Федерация, mogara@rambler.ru, https: //orcid.org/0000-0001-6057-2316 